\title{
Grammatical incongruency and vocabulary types
}

\author{
PASCALE COLE \\ University of Nice Sophia-Antipolis, Nice, France \\ and \\ JUAN SEGUI
}

Laboratory of Experimental Psychology, C.N.R.S., and René Descartes University, Paris, France

\begin{abstract}
Four experiments conducted in French were performed to investigate the role of grammatical congruency and vocabulary class on lexical decision times. In Experiment 1, using a double lexical decision, slower reaction times were found for pairs of words that disagreed in gender or number than for congruent pairs. Experiments 2, 3, and 4 tested this effect with a standard priming procedure. The grammatical congruency effect varied according to presentation times $(130,150$, or $500 \mathrm{msec}$ ) and to vocabulary class of context word (closed or open). Closed-class context words induced stronger grammatical effect than did open-class words. These results suggest that the grammatical link existing between the two words of a pair is more immediately computed when the first one is a closed-class item and argue for a distinct computational role of open-and closedclass words in sentence processing.
\end{abstract}

It is a well-established fact that linguistic context (sentence or single word) influences the processing of a subsequent target word. Historically, psycholinguistic research has investigated more specifically the effects of semantic/associative relations between a prime word and a target word. In a well-known study, Meyer and Schvaneveldt (1971) showed that the identification of a target word was facilitated by the prior presentation of a prime word that was semantically related (e.g., nurse doctor), relative to identification in a control situation with the same target word preceded by an unrelated prime word (e.g., bread doctor).

Subsequent work was conducted to study the effects of formal, phonological, and syntactic relations between prime and target words (e.g., Evett \& Humphreys, 1981; Humphreys, Evett, \& Taylor, 1982; Lukatela, Carello, \& Turvey, 1990). In the latter case, it has been observed that a lexical decision response to a target word is faster when this word is preceded by a congruent syntactic word context (e.g., whose planet) than when it is preceded by an incongruent syntactic word context (e.g., it planet) (Goodman, McClelland, \& Gibbs, 1981; Seidenberg, Waters, Sanders, \& Langer, 1984). As Seidenberg, Tanenhaus, Leiman, and Bienkowsky (1982) emphasized, syntactic context effects, unlike associative or semantic context effects, cannot be attributed to automatic intralexical spreading activation. Crucial evidence for such a

The authors express their thanks to Jonathan Grainger and Jean Louis Juan de Mendoza for their technical assistance. Correspondence should be addressed to Pascale Colé, Laboratory of Experimental Psychology, University of Nice Sophia-Antipolis, 98 Bd. E. Herriot, B.P. 209, 06204 Nice Cédex 3, France. conclusion was provided by studies that showed that the lexical decision task was sensitive to syntactic context, whereas both lexical decision and naming were sensitive to associative and semantic contexts (Carello, Lukatela, \& Turvey, 1988; Groot, 1985; Lukatela et al., 1990; Seidenberg et al., 1984). It has been assumed (Seidenberg et al., 1984; Stanovich \& West, 1983; Tannenhaus \& Donnenwerth-Nolan, 1984; West \& Stanovich, 1982, 1986) that the lexical decision task, unlike the naming task, is more prone to reflect postlexical stages related to lexical-syntactic integration processes. These authors concluded that the associative priming effect results from intralexical activation, whereas the syntactic effect reflects an "automatic" postaccess checking of grammatical congruity between context and target words. This interpretation of the syntactic context effect as a postaccess effect assumes that late decisional processes cannot ignore the output of the syntactic module. If a potential syntactic relation exists between the prime and the target word, this relation is automatically computed even when the experimental procedure requires the subject to focus his or her attention on the target word alone. When this process "detects" a syntactic incongruency, the computation interferes with the lexical decision concerning the target word.

However, an examination of the syntactic context studies only partly supports this interpretation. In particular, the magnitude of the syntactically incongruent context effect differs considerably across experiments. For example, Seidenberg et al. (1984) and Goodman et al. (1981), using a single context word, observed a 13-15msec inhibitory effect. Moreover, this effect was unstable and disappeared when syntactically and semantically 
primed trials were mixed within the same experimental list (Goodman et al., 1981). In contrast, experiments using Serbo-Croatian showed a 30-128-msec inhibitory effect for low-level syntactic context-namely, gender, number, or case disagreement between context and target words (Gurjanov, Lukatela, Moskovljevic, Savic, \& Turvey, 1985; Katz, Boyce, Goldstein, \& Lukatela, 1987; Lukatela, Kostic, Feldman, \& Turvey, 1983; Lukatela, Kostic, Todorovic, Carello, \& Turvey, 1987). Differences obtained between experiments conducted in English and Serbo-Croatian may be due to the fact that Serbo-Croatian possesses a highly developed inflectional system that conveys grammatical information. Thus, grammatical agreement in Serbo-Croatian requires words to be of the same gender, number, and case, and these features are conveyed by inflectional morphemes. In contrast, syntactic information in English depends essentially on word order (Katz et al., 1987). However, the comparison between experiments conducted in English and Serbo-Croatian must be made with caution since the nature of the manipulated "syntactic incongruency" is very different. In particular, experiments conducted in English have used categorical syntactic violations (e.g., whose swear) that necessarily also induce a semantic violation. Thus, the observed inhibitory effects cannot be unambiguously interpreted as the exclusive result of a delay of the decisional system produced by the incongruous information sent by the syntactic processor.

The experiments presented in this article were concerned with the effect of grammatical congruity in the lexical processing of French using two types of inflectional rules: number and gender agreement. This type of experimental material facilitates the correction of the semantic incongruity problem just described.

From a morphosyntactic point of view, French is interesting because it offers an intermediate inflectional system between those of English and Serbo-Croatian (Corbin, 1980). Compared with English, French is considerably richer, in that all sorts of determiners, personal and possessive pronouns, nouns, and adjectives, as well as past participles in certain syntactic contexts, have gender marking. All these categories, as well as auxiliaries and main verbs, are marked for number. Therefore, both gender and number enter in agreement processes and may surface on two different types of items: a closed-class element or an open-class element.

In the experiments presented in this paper, we studied the effect of agreement congruity using open- and closedclass context words. We used two types of word pairs: either two open-class words (i.e., adjective-noun) or one closed-class word and one open-class word (i.e, articlenoun).

The inclusion of these two types of syntactic pairs is interesting, since some processing models of language perception and production assign computationally distinct roles to open- and closed-class words. According to Garrett $(1976,1979)$, during sentence processing, closed-class words are immediately used to compute syntactic rela- tions since these words primarily convey this kind of information. In contrast, open-class words primarily convey lexical-semantic information and are used to establish the meaning representation of the sentence. In the same vein, Cutler, Hawkins, \& Gilligan (1985) assume that lexical and affixal information conveyed by a morphologically complex word are processed separately. Furthermore, these authors have proposed that lexical-semantic information, conveyed by the stem, has computational priority over the syntactic information conveyed by the affix. In other words, subjects process stems before affixes. For instance, given the open-class word dogs, the processing of the lexical-semantic information of the root $d o g$ has computational priority over the syntactic information of the affix $s$. This view of the processing of inflectional information was defended by Katz et al. (1987) in interpreting the effect of grammatical information in auditory word recognition.

Given the differential computational role attributed by these theoretical models to open- and closed-class words, we assume that the syntactic relation between a closedclass word and an open-class word should be more immediately established and stronger than the syntactic relation existing between two open-class words. In other words, closed-class words may be more syntactically bound than open-class words in the same context. Consequently, the same type of grammatical violation (gender/number agreement) may be more disruptive for the processing of closed-open-class pairs than for the processing of open-open-class pairs.

\section{EXPERIMENT 1}

In Experiment 1, subjects received pairs of words corresponding to a minimal syntactic sequence. Words of the pair could either agree or disagree in gender or number; however, in all cases, the pair constituted a semantically plausible structure. The potential influence of the vocabulary type of words was examined using pairs of words composed of two open-class words (open-open pairs) and pairs of words composed of a closed-class word followed by an open-class word (closed-open pairs).

\section{Method}

Design and Stimuli. Pairs of words were selected such that the two words either agreed in number and gender (e.g., joli chat) or disagreed in number (e.g., jolis chat) or in gender (e.g., jolie chat). The grammatical transgression was conveyed for open-open pairs by the inflectional morpheme of the first word of the pair. The second word was always a noun in neutral masculine singular form. This form corresponds to the citation form in French. It is important to note that these gender and number markings are overtly expressed only in written French.

Half of the 360 test pairs had a first word belonging to the openclass category (e.g., joli chat), and half had a first word belonging to the closed-class category (e.g., mon chat). Only adjectives were used when the first elements were open-class words. The closedclass first words included possessive adjectives, demonstrative adjectives, definite articles, and exclamatories. The frequency of these closed-class first elements was clearly much higher than the fre- 
Table 1

The Six Experimental Situations of Experiment 1 as a Function of Grammatical Relation and Vocabulary Type of First Words of Pairs

\begin{tabular}{lccc}
\hline $\begin{array}{l}\text { Vocabulary } \\
\text { Type }\end{array}$ & $\begin{array}{c}\text { Gender } \\
\text { Transgression }\end{array}$ & $\begin{array}{c}\text { Number } \\
\text { Transgression }\end{array}$ & $\begin{array}{c}\text { Control } \\
\text { Congruent }\end{array}$ \\
\hline $\begin{array}{ccc}\text { Open class } \\
\text { Closed class }\end{array}$ & jolie chat & jolis chat & joli chat \\
ma chat & mes chat & mon chat \\
\hline
\end{tabular}

quency of the open-class first elements, reflecting differences in frequency distribution for these two classes of words in the language. The mean frequency of the open-class first words was 171 occurrences per million (Trésor de la Langue Française, 1971), and they were between 3 and 10 letters long (mean length $=6$ letters). The mean frequency of the first closed-class words was 6,014 occurrences per million, and they varied from 2 to 6 letters long (mean length $=3$ letters). The mean frequency of the second word, which was the same for open-open and closed-open pairs, was 21 occurrences per million, and they varied from 3 to 8 letters long (mean length $=6$ letters).

The three levels of the grammatical relation factor (gender transgression, number transgression, and control congruent) and the two levels of the vocabulary type factor (open-open/closed-open) were within-subject factors. However, a particular word was presented only one time to a given subject. As shown in Table 1, the same second word was associated with six different experimental cases. In order to counterbalance the presentation of the experimental material, six experimental lists were constructed, each composed of 60 test pairs and 90 filler pairs (30 word-word pairs, 30 wordnonword pairs, and 30 nonword-nonword pairs). This led to six independent groups of subjects.

Procedure. The two letter strings of the pairs were presented simultaneously, centered on the screen of an Olivetti M24 computer, after a fixation point had appeared for $300 \mathrm{msec}$. The pairs remained on the screen until the subjects responded. The two letter strings were presented in lowercase. The subjects were instructed to make a double lexical decision as rapidly and as accurately as possible, responding "yes" (by pressing one of the two response buttons with the forefinger) if and only if the two letter strings of the pair were French words and "no" (with the forefinger of the other hand) if at least one letter string was not a French word. The experimental lists were preceded by a practice list of 20 different pairs.

Subjects. Sixty students from the René Descartes University and the Ecole des Psychologues Praticiens of Paris served as subjects. They were all native speakers of French.

\section{Results}

Average double lexical decision latencies and percent errors are given in Table 2 . As can be seen, responses corresponding to grammatically congruent pairs were faster than responses to grammatically incongruent pairs (804 vs. $875 \mathrm{msec}$ ), and pairs with a closed-class first word were responded to more quickly than were pairs with an open-class first word ( $806 \mathrm{vs} .890 \mathrm{msec})$. An analysis of variance (ANOVA) was performed on these data using subjects $(F 1)$ and items $(F 2)$ as random variables. No reaction time (RT) was excluded from this analysis. The two main factors, grammatical relation and vocabulary type, introduced a significant effect [for grammatical relation, $F 1(2,108)=45.22, p<.0005, F 2(2,118)=$ $28.18, p<.0005$; for vocabulary type, $F 1(2,54)=$ $53.41, p<.0005, F 2(1,59)=67.57, p<.0005]$. The interaction between these factors was marginally significant in the subject analysis only $[F 1(2,108)=2.7, p<$ .10].

Given that the nature of the agreement transgression (gender and number) did not introduce significant effects at a global or at a more specific level-the 22-msec difference between gender and number transgression for closedopen pairs was only marginally significant in the subject analysis $[F 1(1,54)=3.94, p<.10 ; F 2(1,59)<1]-$ data concerning these two conditions were collapsed.

This analysis showed a significant effect of the two new main factors, grammatical congruency and vocabulary type. RTs to control congruent pairs were significantly faster than RTs to incongruent pairs $[F 1(1,54)=89.77$, $p<.0005 ; F 2(1,59)=53.79, p<.0005]$, and RTs to closed-open pairs were significantly faster than RTs to open-open pairs $[F 1(1,54)=42.98, p<.0005$; $F 2(1,59)=69.09, p<.0005]$. The interaction between grammatical congruency and vocabulary type was marginally significant in the subject analysis $[F 1(1,54)=$ $3.94, p<.10 ; F 2(1,59)<1$ ]. Planned comparisons showed the presence of a congruency effect for open-open pairs $[F 1(1,54)=49.56, p<.0005 ; F 2(1,59)=36.94$, $p<.0005]$ and for closed-open pairs $[F 1(1,54)=25.90$, $p<.0005 ; F 2(1,59)=28.75, p<.0005]$.

As can be seen in Table 2, the error rates followed the same global pattern as the RT data concerning the role of the grammatical congruency factor $[F 1(1,54)=45.25$, $p<.0005 ; F 2(1,59)=56.15, p<.0005]$. However, the vocabulary type factor did not introduce a significant effect $[F 1(1,54)<1 ; F 2(1,59)=1.8]$. The interaction between these two factors was not significant $[F 1(1,54)=$ $1.68, p>.20 ; F 2(1,59)=2.98, p<.10]$.

\section{Discussion}

A significant effect of grammatical congruency was observed in Experiment 1. Pairs of words that were in full grammatical agreement were associated with faster double lexical decision judgments than were pairs of words

Table 2

Experiment 1: Reaction Times (RTs; in Milliseconds), Percent (\%) Errors, and Standard Errors (SEs) to Pairs Affected by a Grammatical Relation and Varying in the Vocabulary Type of the First Word

\begin{tabular}{|c|c|c|c|c|c|c|c|c|c|}
\hline \multirow{3}{*}{$\begin{array}{c}\text { Vocabulary } \\
\text { Type }\end{array}$} & \multicolumn{9}{|c|}{ Grammatical Relation } \\
\hline & \multicolumn{3}{|c|}{ Gender Transgression } & \multicolumn{3}{|c|}{ Number Transgression } & \multicolumn{3}{|c|}{ Control Congruent } \\
\hline & RT & $\%$ Errors & $S E$ & RT & $\%$ Errors & $S E$ & RT & $\%$ Errors & $S E$ \\
\hline Open class & 920 & 4.8 & 15.92 & 915 & 6.8 & 14.63 & 835 & 3.0 & 14.60 \\
\hline Closed class & 834 & 9.2 & 15.83 & 812 & 6.5 & 16.79 & 773 & 2.7 & 16.99 \\
\hline
\end{tabular}


that disagreed on a grammatical dimension (number or gender). These data strongly suggest that the subjects could not ignore the general characteristics of grammatical agreement that link the elements of a semantically plausible minimal structure. A compatibility checking of gender and/or number agreement between the two words of a sequence seems to be computed automatically even though the experimental task did not require such processing. The low overall error rate $(5 \%)$ indicates that the task was clearly understood by the subjects as a double lexical decision task and not as a grammatical judgment task. These results are consistent with previous ones obtained in Serbo-Croatian manipulating inflectional rules (Gurjanov et al., 1985; Lukatela, Gligorijevic, Kostic, \& Turvey, 1980; Lukatela et al., 1983; Lukatela et al., 1982).

The nature of the agreement transgression (number or gender) does not introduce a significant effect, but RTs to closed-open pairs were faster than RTs to open-open pairs for control and incongruent items.

Given the nature of the experimental task (a double lexical decision), the effect of the vocabulary type factor observed for both control and incongruous pairs may be related to a difference in frequency and length between the first element of the two types of sequences $(6,014$ occurrences per million for closed-open sequences, and 171 occurrences per million for open-open sequences).

Finally, and contrary to our expectations, the magnitude of the effect of grammatical congruency was analogous for the two types of vocabulary pairs. As noted in the introduction, we expected a larger congruity effect for closed-open pairs than for open-open pairs. We assume that this absence of difference may be due to the use of a double lexical decision procedure. In this procedure, the two words of each pair were presented simultaneously and remained on the screen until the subject made a response. This may have led to a ceiling effect. To test this interpretation, a second experiment was conducted with a more standard priming procedure, making it possible to control the presentation time of the context word.

In Experiment 2, the context word was presented for $500 \mathrm{msec}$, followed immediately by the target item. The subjects performed a single lexical decision task on this target. In this condition, the time available to compute a syntactic relation between the context and the target word before making a lexical decision on the target was reduced. According to our hypothesis, the agreement relation between the context and the target word may be evaluated more rapidly when the context is a closed-class word than when it is an open-class word. Consequently, the shorter presentation times of the context word may affect the pairs of open-class words more than the pairs with a closed-class word and an open-class word. We propose that with the closed-class context the assessment of the grammatical relation between this item and the target takes place immediately and affects the lexical decision judgment. In contrast, when the context item is an openclass word, the computation of the grammatical relation may in some trials not be available to the system when the target word arrives. In these cases, the lexical decision judgment on the target word would not be affected by the agreement violation.

\section{EXPERIMENT 2}

\section{Method}

Design and Stimuli. Pairs of words were selected from the set used in Experiment 1. As in Experiment 1, grammatical relation and vocabulary type of context word were the within-subject factors. The open-class context words were from 3 to 8 letters long (mean length $=6$ letters), and their average frequencies were 207 occurrences per million. The closed class context words, which belonged to the same grammatical categories as in Experiment 1, were from 2 to 6 letters long (mean length $=3$ letters), and their average frequencies were 6,014 occurrences per million. The test words varied from 3 to 8 letters long (mean length $=6$ letters), and their average frequencies were 60 occurrences per million. Six experimental lists were constructed, each composed of 60 test pairs and 60 filler pairs ( 30 word-word pairs and 30 word-nonword pairs). As in Experiment 1, a preliminary training of subjects was done, and six independent groups of subjects were used.

Procedure. Stimuli were presented sequentially. Each trial consisted of the following sequence of stimuli: A fixation point appeared in the center of the screen of an AT computer for $300 \mathrm{msec}$, followed by a context word, or "prime," presented for $500 \mathrm{msec}$, which in turn was immediately replaced by a target string (word or nonword) that remained on the screen until the subjects responded. Context words and target stimuli were both presented in lowercase. The subjects were asked to perform a lexical decision task only on the second stimulus of the sequence. The remaining procedure was the same as that for Experiment 1.

Subjects. Sixty students from the Department of Psychology at the University of Nice received course credit for their participation in the experiment. All were native speakers of French.

\section{Results}

Average lexical decision latencies for correct responses and percent errors to target words are given in Table 3. An ANOVA was performed using subjects $(F 1)$ and items $(F 2)$ as the random factors. RTs exceeding $1,500 \mathrm{msec}$ were excluded from the analysis (1.2\% of the data).

The main effects of grammatical relation $[F 1(2,108)=$ $16.69, p<.0005 ; F 2(2,58)=11.54, p<.005]$ and of vocabulary type $[F 1(1,54)=10.89, p<.005$;

Table 3

Experiment 2: Reaction Times (RTs; in Milliseconds), Percent (\%) Errors, and Standard Errors (SEs) to Target Words Belonging to Pairs Affected by a Grammatical Relation and Varying in the Vocabulary Type of the Context Word

\begin{tabular}{|c|c|c|c|c|c|c|c|c|c|}
\hline \multirow{2}{*}{$\begin{array}{c}\text { Vocabulary } \\
\text { Type }\end{array}$} & \multicolumn{3}{|c|}{ Gender Transgression } & \multicolumn{3}{|c|}{ Number Transgression } & \multicolumn{3}{|c|}{ Control Congruent } \\
\hline & RT & \% Errors & $S E$ & RT & $\%$ Errors & $S E$ & RT & \% Errors & $S E$ \\
\hline & 62 & & & 624 & & & & 0.8 & 12.82 \\
\hline Closed class & 660 & 0.6 & 17.60 & 647 & 1.1 & 20.85 & 593 & 1.5 & 11.99 \\
\hline
\end{tabular}


$F 2(1,29)=10.51, p<.0057$ were significant, but the interaction between these two main factors did not reach significance (all $F \mathrm{~s}<1$ ). As in Experiment 1, the nature of the agreement transgression (number or gender) did not introduce a significant effect $(F<1)$, and the data of these two conditions were collapsed.

The congruent control pairs were responded to $54 \mathrm{msec}$ faster than were the incongruent pairs $[F 1(1,54)=46.43$, $p<.005 ; F 2(1,29)=36.10, p<.0005]$. The RTs to open-open pairs were faster than the RTs to closed-open pairs $[F 1(1,54)=12.34, p<.001 ; F 2(1,29)=9.72$, $p<.005]$. The interaction between grammatical congruency and vocabulary type was not significant $[F 1(1,54)$ $=1.75, p>.20 ; F 2(1,29)=0.22]$. The grammatical congruency effect was observed for both open-open pairs $[F](1,54)=22.45, p<.0005 ; F 2(1,29)=22.89, p<$ $.0005]$ and closed-open pairs $[F 1(1,54)=28.51, p<$ $.0005 ; F 2(1,29)=18.04, p<.0005]$. However, the RT difference between congruent and incongruent pairs was greater for closed-open pairs than for open-open ones. Planned comparisons showed that RTs to open-open pairs differed significantly from RTs to closed-open pairs in the grammatical incongruent condition $[F 1(1,54)=10.46$, $p<.005 ; F 2(1,29)=7.92, p<.01]$ and differed only marginally in the congruent control condition $[F 1(1,54)=$ $2.94, p<.10 ; F 2(1,29)=3.53, p<.10]$.

The error rates analysis revealed a significant effect of the grammatical congruency factor only in the item analysis $[F 1(1,54)=2.49, p>.12 ; F 2(1,29)=4.57, p<$ $.05]$ and a significant interaction between the two main factors only in the subject analysis $[F 1(1,54)=4.67, p<$ $.05 ; F 2<1]$.

\section{Discussion}

The main result of Experiment 1 was replicated in Experiment 2. An average 54-msec effect of grammatical violation was obtained. In agreement with our predictions, the results of Experiment 2 showed a larger effect of grammatical incongruency for items with a closed-class context word than for items with an open-class context word. However, the magnitude of this difference between incongruous closed-open pairs and open-open pairs was relatively reduced $(13 \mathrm{msec})$. We therefore decided to confirm the differential role of open- and closed-class context word on syntactic computation in a third experiment using a shorter presentation time of the context word $(150 \mathrm{msec})$.

\section{EXPERIMENT 3}

\section{Method}

Design and Stimuli. The material and stimuli were the same as those used in Experiment 2.

Procedure. The procedure was the same as in Experiment 2, but context words were presented for $150 \mathrm{msec}$ (instead of $500 \mathrm{msec}$, as in Experiment 2).

Subjects. Sixty students from the Department of Psychology at the University of Nice took part in the experiment. All were native speakers of French.

\section{Results}

Latencies longer than $1,500 \mathrm{msec}$ were excluded from analysis ( $1.5 \%$ of the data). Average lexical decision latencies (in milliseconds) and percent errors to target words are given in Table 4. An ANOVA was performed on these data using subjects $(F 1)$ and items $(F 2)$ as the random variables.

The main effect of grammatical relation was significant in the subject analysis and marginally significant in the item analysis $[F 1(2,108)=13.51, p<.0005 ; F 2(2,58)=$ $3.68, p<.10]$, as was the effect of vocabulary type $[F 1(1,54)=7.44, p<.01 ; F 2(1,29)=1.55, p>.22]$. The interaction between these two main factors was not significant $[F 1(2,108)=1.78, p>.17 ; F 2<1]$.

As in Experiments 1 and 2, the nature of the agreement violation (number or gender) did not lead to significant differences [for open-class context word, $F 1<1, F 2<1$; for closed-class context word, $F 1(1,54)=1.4, F 2(1,29)=$ 1.23], and data from these two conditions were collapsed. RTs to congruent items were faster than RTs to incongruent items $[F 1(1,54)=28.98, p<.0005 ; F 2(1,29)=$ $8.80, p<.01]$, and RTs to open-open pairs were faster than RTs to closed-open pairs only in the subjects analysis $[F 1(1,54)=4.58, p<.05 ; F 2(1,29)=1.09]$. The interaction between grammatical congruency and vocabulary type was marginally significant in the subjects analysis $[F 1(1,54)=3.03, p<.10 ; F 2<1]$. Planned comparisons showed that the grammatical congruency effect was obtained for the two types of context words [for items with an open-class context word, $F 1(1,54)=6.39, p<$ $.025 ; F 2(1,29)=1.50, p>.23$; for items with a closedclass context word, $F 1(1,54)=25.55, p<.0005$, $F 2(1,29)=8.76, p<.01]$.

It is clear from Figure 1 that the effect of grammatical congruency was greater for targets preceded by a closedclass word than for targets preceded by an open-class word

Table 4

Experiment 3: Reaction Times (RTs; in Milliseconds), Percent (\%) Errors, and Standard Errors (SEs) to Target Words Belonging to Pairs Affected hy a Grammatical Relation and Varying in the Vocabulary Type of the Context Word

\begin{tabular}{|c|c|c|c|c|c|c|c|c|c|}
\hline \multirow{3}{*}{$\begin{array}{c}\text { Vocabulary } \\
\text { Type }\end{array}$} & \multicolumn{9}{|c|}{ Grammatical Relation } \\
\hline & \multicolumn{3}{|c|}{ Gender Transgression } & \multicolumn{3}{|c|}{ Number Transgression } & \multicolumn{3}{|c|}{ Control Congruent } \\
\hline & RT & $\%$ Errors & $S E$ & $\mathrm{RT}$ & $\%$ Errors & $S E$ & RT & $\%$ Errors & $S E$ \\
\hline Open class & 624 & 1.1 & 16.13 & 628 & 1.1 & 17.28 & 601 & 2.3 & 15.08 \\
\hline Closed class & 663 & 2.3 & 16.15 & 645 & 1.7 & 18.29 & 605 & 2.3 & 16.21 \\
\hline
\end{tabular}




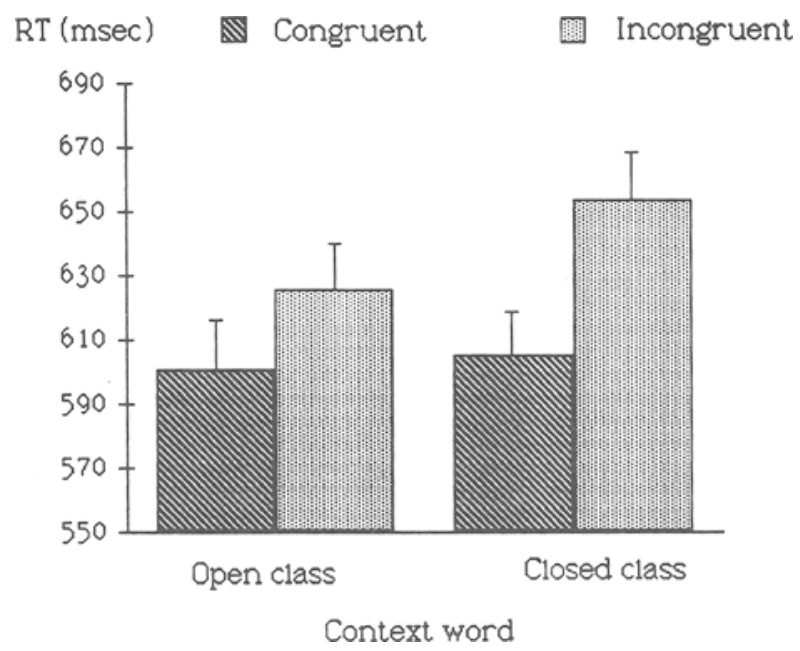

Figure 1. Mean reaction times in milliseconds as a function of grammatical congruency and vocabulary type of context in Experiment 3. Vertical bars represent standard errors.

(49 vs. $25 \mathrm{msec}$ ). In fact, RTs to open-open pairs differed significantly from RTs to closed-open pairs in the grammatical incongruency pairs $[F 1(1,54)=8.87, p<$ $.005 ; F 2(1,29)=3.39, p<.10]$ but not in the control pairs $(F 1<1$ and $F 2<1)$. As can be seen in Figure 1, RTs to congruent items are practically identical to RTs to open-open and closed-open pairs.

The subject and item analysis of the error rates revealed no significant differences (all $F$ s $<1$ ).

\section{Discussion}

The observed results agree with our expectations: The reduction of presentation time of the context word affected differentially open-open pairs and closed-open pairs. Even if the interaction between vocabulary type and syntactic congruency was still not statistically significant, the effect of grammatical congruency was clearly greater (single to double) when the prime was a closed-class word than when it is an open-class word. According to our interpretation, these results indicate that the computation of the grammatical relation existing between two sequentially presented words is more immediately established when the first item corresponds to a closed-class word than when it corresponds to an open-class word.

However, one might argue that the more important grammatical congruity effect observed with closed-class context words is not due to their linguistic role but rather to a confound factor-namely, their very high frequency. More precisely, given that closed-class context words are more frequent than are open-class words, it is possible to assume that the observed differences between experimental pairs are related to a difference in the recognition time for a closed and an open context word. If the recognition of a closed-class context word is faster than the recognition of an open-class one, one might argue that the possibility to establish a grammatical link between the context and the target word is greater in the first case than in the second.

Experiment 4 was designed to test this alternative interpretation of our results using open- and closed-class context words closely matched on frequency and length.

\section{EXPERIMENT 4}

\section{Method}

Design and Stimuli. As in Experiments 2 and 3, grammatical congruency and vocabulary type of context word were the withinsubject factors. The grammatical transgression concerned only gender transgression. The open- and closed-class context words were matched as closely as possible on length and frequency. The average frequencies of open-class context words were 392 occurrences per million and were from 3 to 8 letters long (mean length $=5.2$ letters). The average frequencies of the closed-class context words were 387 occurrences per million and were from 2 to 6 letters long (mean length $=4.1$ letters). The grammatical categories of these two types of context word were the same as in Experiments 1-3. The singular masculine noun targets were from 3 to 7 letters long (mean length $=5.5$ letters), and their average frequencies were 45 occurrences per million. The four experimental lists were composed of 20 test pairs and 60 filler pairs ( 30 word-word pairs and 30 word-nonword pairs). The subjects were given 20 practice pairs in a training session. Four groups of subjects were used.

Procedure. The procedure was the same as in Experiments 2 and 3 , but the time duration of context words was reduced to $130 \mathrm{msec}$.

Subjects. Twenty-four University of Nice students served as subjects. They all were native speakers of French. None had participated in the previous experiments.

\section{Results and Discussion}

The results are presented in Figure 2. Latencies longer than $1,500 \mathrm{msec}$ were excluded from the analysis $(1.2 \%$ of the data). An ANOVA performed on lexical decision times and percent errors showed a 30-msec significant effect of grammatical congruency $[F 1(1,23)=14.4, p<$ $.001 ; F 2(1,19)=11.33, p<.005]$ and no effect of vocabulary type $(F 1<1, F 2<1)$. The interaction be-

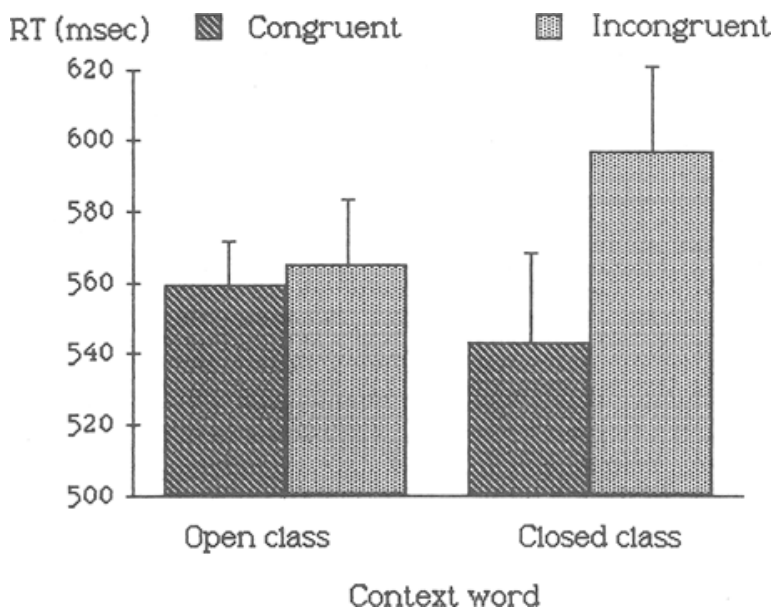

Figure 2. Mean reaction times in milliseconds as a function of grammatical congruency and vocabulary type of context in Experiment 4. Vertical bars represent standard errors. 
tween these two main factors was significant $[F 1(1,23)=$ $4.98, p<.03 ; F 2(1,19)=3.85, p<.06]$.

Planned comparisons indicated a significant effect of grammatical transgression for closed-open pairs $[F 1(1,23)$ $=16.64, p<.0005 ; F 2(1,19)=12.7, p<.005]$ and no effect for open-open pairs $(F<1, F 2<1)$. The error rates analysis revealed no significant effect.

The interaction between the two main factors (grammatical congruency and vocabulary type of the context word) was now significant. More importantly, the interaction observed between open-open and closed-open pairs with regard to the grammatical congruency effect cannot be attributed to differences in length and frequency between open- and closed-class context words since a close matching was done between these items.

\section{GENERAL DISCUSSION}

Two main results obtained in our experiments are to be emphasized. The first one concerns the fact that the grammatical congruency between two words influences the processing of the lexical items both in a double lexical decision task (Experiment 1 ) and in a primed lexical decision task (Experiments 2, 3, and 4). The inhibitory effect obtained for items that violate the number/gender agreement confirms the role of syntactic parameters on lexical decisions. The second main result obtained in these experiments is consistent with a syntactic interpretation of the observed effects. This result corresponds to the fact that the relative magnitude of the observed congruency effect depends on the syntactic category of the context word. When a number or gender agreement rule is violated between a closed-class word and an open-class word, the effect is larger than when the context and the target words are both open-class items. Empirical evidence of processing differences for these two types of vocabulary item have been previously observed when these items were included in a sentence structure (Friedericci, 1985; Greenberg \& Koriat, 1991; Koriat \& Greenberg, 1991; Koriat \& Greenberg, 1993; Koriat, Greenberg, \& Goldshmid, 1991; Van Petten \& Kutas, 1991) but not when they were presented in isolation (Gordon \& Caramazza, 1982, 1983; Segui, Frauenfelder, Lainé, \& Mehler, 1987; Segui, Mehler, Frauenfelder, \& Morton, 1982; Taft, 1990). This contrast suggests that the effect of vocabulary type is related to the "actual" functional role of the open- and closed-class words during sentence processing rather than to an eventual difference in the specific retrieval mechanisms associated to these two classes of words. An analogous distinction was advanced recently by Koriat and collaborators in a series of papers (cited above) about the missing-letter effect. Koriat et al.'s experiments showed that the missing-letter effect was more important for function words (closed-class words) than for content words (open-class words). Moreover, when function words were embedded in a phrase where they were forced into a content role by the context, letter detection did not differ from that of matched content words. The observed difference was related to the word func- tion and not to the word form. This result cannot be interpreted in terms of the relative frequency of the function or the content carrier-letter target word since it was observed when the frequency of these two types of word was equated. Koriat et al. proposed a structural model in which function words or morphemes are initially utilized to define the structural frame of a phrase. Subsequently, the computed syntactic units are lost in the transition from structure to meaning.

To interpret the fact that the effect of agreement violations between a closed-class word and an open-class word was stronger than that between two open-class words observed in Experiments 2, 3, and 4, we proposed that, when the context word is presented for a short time, the grammatical link existing between this word and the open-class target word is more immediately computed than when the context word is constituted by an open-class word. Consequently, in this experimental condition, the output of the syntactic processor is more likely to affect lexical decisions when targets are preceded by a closed-class word than when targets are preceded by an open-class word. According to this interpretation, syntactic and lexicalsemantic computations are elaborated independently; however, if the "negative" result of the syntactic processor is available before the lexical decision on the target word is made, this decision may be delayed. This postaccess interpretation is compatible with the fact that the magnitude of the vocabulary type effect varies as a function of the presentation time of the context word. According to this interpretation, semantic information and syntactic information are encoded by two distinct components: a lexical-semantic component and a syntactic component.

This hypothesis of autonomy of the syntactic processor was previously proposed on the basis of results obtained in Serbo-Croatian. In these experiments, an inhibitory effect of flectional inconsistency was observed using pseudowords as experimental context items (Gurjanov et al., 1985; Katz et al., 1987).

At a more general theoretical level, the results obtained in the experiments presented in this paper favor a modular view of language processing (Forster, 1979), according to which different types of structural information are processed by separate subcomponents of the language processing system.

\section{REFERENCES}

Carello, C., Lukatela, G., \& Turvey, M. T. (1988). Rapid naming is affected by association but not by syntax. Memory \& Cognition, 16, 187-195.

Corrin, D. (1980). Compétence lexicale et compétence syntaxique. Modèles Linguistiques, 2, 52-138.

Cutler, A., Hawkins, J. A., \& Gilligan, G. (1985). The suffixing preference: A processing explanation. Linguistics, 23, 723-758.

DE GROOT, A. M. B. (1985). Word-context effects in word naming and lexical decision. Quarterly Journal of Experimental Psychology, 37A, 281-297.

EVETT, L. J., \& Humphreys, G. W. (1981). The use of abstract graphemic information in lexical access. Quarterly Journal of Experimental Psychology, 33A, 325-350.

FORSTER, K. I. (1979). Levels of processing and the structure of lan- 
guage processor. In W. E. Cooper \& E. C. Walker (Eds.), Sentence processing (pp. 27-85). Hillsdale, NJ: Erlbaum.

FRIEDERICI, A. D. (1985). Levels of processing and vocabulary types: Evidence from on-line comprehension in normal and agrammatics. Cognition, 19, 133-166.

GARRETT, M. F. (1976). Syntactic processes in sentence production. In E. C. Walker \& R. Wales (Eds.), New approaches to language mechanisms (pp. 231-255). Amsterdam: North-Holland.

GARRETT, M. F. (1979). Word and sentence perception. In R. Held, H. W. Leibowicz, \& H. L. Tueber (Eds.), Handbook of sensory physiology: Perception (Vol. 8, pp. 611-625). New York: Springer Verlag.

Goodman, G. C., McClelland, J. L., \& GibBs, R. W. (1981). The role of syntactic context in word recognition. Memory \& Cognition, 9, 580-586.

Gordon, B., \& Caramazza, A. (1982). Lexical decision for open- and closed-class words: Failure to replicate frequency sensitivity. Brain \& Language, 15, 143-160.

Gordon, B., \& Caramazza, A. (1983). Closed- and open-class lexical access in agrammatic and fluent aphasics. Brain \& Language, 19, 335-345.

GreEnberg, S. N., \&oriat, A. (1991). The missing letter effect for common function words depends on their linguistic function in the phrase. Joumal of Experimental Psychology: Learning, Memory, \& Cognition, 17, 1051-1061.

Gurjanov, M., Lukatela, G., Moskovluevic, J., Savic, M., \& TURVEY, M. T. (1985). Grammatical priming of inflected nouns by inflected adjectives. Cognition, 19, 55-71.

Humphreys, G. W., EveTt, L. J., \& TAYlor, D. E. (1982). Automatic phonological priming in visual word recognition. Memory \& Cognition, 10, 576-590.

Katz, L., Boyce, S., Goldstein, L., \& Lukatela, G. (1987). Grammatical information effects in auditory word recognition. Cognition, $25,235-263$.

Koriat, A., Greenberg, S. N. (1991). Syntactic control of letter detection: Evidence from English and Hebrew nonwords. Journal of Experimental Psychology: Learning, Memory, \& Cognition, 17, 1035-1050.

Koriat, A., \& Greenberg, S. N. (1993). Prominence of leading functors in function morpheme sequences as evidenced by letter detection. Journal of Experimental Psychology: Learning, Memory, \& Cognition, 19, 34-50.

Koriat, A., Greenberg, S. N., \& Goldshmid, Y. (1991). The missing letter effect in Hebrew: Word frequency or word function. Journal of Experimental Psychology: Learning, Memory, \& Cognition, 17, 66-80

Lukatela, G., Carello, C., \& Turvey, M. T. (1990). Phonemic, associative, and grammatical context effects with identified and unidentified primes. Language \& Speech, 33, 1-18.

Lukatela, G., Gugoruevic, B., Kostic, A., \& Turvey, M. T. (1980). Representation of inflected nouns in the internal lexicon. Memory \& Cognition, 8, 336-344.
Lukatela, G., Kostic, A., Feldman, L., \& Turvey, M. T. (1983). Grammatical priming of inflected nouns. Memory \& Cognition, 11. 59-63.

lukatela, G., Kostic, A., Todorovic, D., Carello, C., \& Turvey, M. T. (1987). Type and number of grammatical violations and the grammatical congruency effect in lexical decision. Psychological Research, 49, 37-43.

Lukatela, G., Moraca, J., Stojnov, D., Savic, M., Katz, L., \& TURVEY, M. T. (1982). Grammatical priming effects between pronouns and inflected verb forms. Psychological Research, 44, 297-311.

Meyer, D. E., \& Schvaneveldt, R. W. (1971). Facilitation in recognizing pairs of words: Evidence of a dependence between retrieval operations. Journal of Experimental Psychology, 90, 227-334.

Segui, J., Frauenfelder, U., Lainé, C., \& MeHler, J. (1987). The word frequency effect for open and closed class items. Cognitive Neuropsychology, 4, 33-44.

Segui, J., Mehler, J., Frauenfelder, U., \& Morton, J. (1982). The word frequency effect and lexical access. Neuropsychologia, 20, 615-627.

Seidenderg, M. S., Tanenhaus, M. K., Leiman, J. M., \& BIENKOWSKI, M. (1982). Automatic access of the meanings of ambiguous words in context: Some limitations of knowledge-based processing. Cognitive Psychology, 14, 489-537.

Seidengerg, M. S., Waters, G. S., Sanders, M., \& Langer, P. (1984). Pre- and postlexical loci of contextual effects on word recognition. Memory \& Cognition, 12, 315-328.

STANOVICH, K. E., \& WEST, R. F. (1983). On priming by a sentence context. Journal of Experimental Psychology: General, 112, 1-36.

TAFT, M. (1990). Lexical processing of functionally constrained words. Journal of Memory \& Language, 29, 245-257.

TANenhaus, M. K., Donnenwerth-Nolan, S. (1984). Syntactic context and lexical access. Quarterly Joumal of Experimental Psychology, 36A, 649-661.

Trésor de la langue Française. (1971). Nancy, France: Centre de la Recherche Scientifique.

VAN Petten, C., \& Kutas, M. (1991). Influences of semantic and syntactic context on open- and closed-class words. Memory \& Cognition, 19, 95-112.

West, R. F., \& Stanovich, K. E. (1982). Source of inhibition in experiments on the effect of sentence context on word recognition. Journal of Experimental Psychology: Leaming, Memory, \& Cognition, 5, 385-399.

West, R. F., Stanovich, K. E. (1986). Robust effects of syntactic structure on visual word processing. Memory \& Cognition, 12, 31-45.

(Manuscript received July 26, 1993; revision accepted for publication August 25, 1993.) 